\title{
Multi-level Diabetes Prevention and Treatment Interventions for Native People in the USA and Canada: a Scoping Review
}

\author{
Sarah A. Stotz ${ }^{1} \cdot$ Kristie McNealy $^{2} \cdot$ Rene L. Begay $^{1} \cdot$ Kristen DeSanto $^{3} \cdot$ Spero M. Manson $^{1} \cdot$ Kelly R. Moore $^{1}$
}

Accepted: 2 August 2021 / Published online: 7 November 2021 / Published online: 7 November 2021

(c) The Author(s), under exclusive licence to Springer Science+Business Media, LLC, part of Springer Nature 2021

\begin{abstract}
Purpose of Review This scoping literature review seeks to answer the question "What is known in the existing literature about multi-level diabetes prevention and treatment interventions for Native people living in the United States and Canada?" Recent Findings Multi-level interventions to prevent and/or treat chronic diseases, such as diabetes, promise to help individuals who experience health disparities related to social determinants of health. As described by the socio-ecological model, such interventions mobilize support through a combination of individual, interpersonal, organizational, community, and policy levels of activity.

Summary This review revealed little literature about multi-level diabetes prevention and/or treatment programs for US and Canada-based Native peoples. Ten interventions were identified; all focused on diabetes prevention; eight were specific to youth. Multi-level intervention design elements were largely individual-, school-, and community-based. Only three interventions included environmental or policy-level components.
\end{abstract}

Keywords Multi-level intervention · Diabetes prevention · Diabetes treatment $\cdot$ American Indian $\cdot$ Alaska Native $\cdot$ First Nations

This article is part of the Topical Collection on Diabetes Epidemiology

Sarah A. Stotz

Sarah.Stotz@cuanschutz.edu

Kristie McNealy

KMcNealy@EconometricaInc.com

Rene L. Begay

Rene.begay@ cuanschutz.edu

Kristen DeSanto

Kristen.desanto@cuanschutz.edu

Spero M. Manson

Spero.manson@cuanschutz.edu

Kelly R. Moore

Kelly.moore@cuanschutz.edu

1 Centers for American Indian and Alaska Native Health, Colorado School of Public Health, University of Colorado Anschutz Medical Campus, 13055 East 17thAve, Aurora, CO 80045, USA

2 Econometrica, Inc., Bethesda, MD, USA

3 Strauss Health Sciences Library, University of Colorado Anschutz Medical Campus, 13055 East 17th Ave, Aurora, CO 80045, USA

\section{Introduction}

Native peoples in the USA and Canada have the highest prevalence of diabetes among all racial/ethnic groups [1] and bear a significant burden of comorbidities. In the USA, diabetes prevalence is two times higher among US-based Native people-referred to here as American Indians and Alaska Natives (AI/AN) - than non-Hispanic white individuals (14.7\% vs. $7.5 \%$ ) [2] and has increased more than $50 \%$ since the mid-1990s [3, 4]. In Canada, between 1995 and 2014, the prevalence and incidence of diabetes were significantly higher for First Nations people than their non-First Nations counterparts, particularly among younger women and children [5]. The well-documented socioeconomic disparities that plague these populations affect their risk of diabetes. For example, outcomes among AI/AN participants in the Special Diabetes Program for Indians Diabetes Prevention Demonstration Project (SDPI-DP) found that those who had lower income and were enrolled in a lifestyle intervention lost less weight and achieved a lower reduction in unhealthy food consumption [6].

In the USA and Canada, AI/AN and First Nations members have a high prevalence of diabetes complications $[1,2,5$, 
7-12], including hypertension, cerebrovascular disease, renal failure, and lower-extremity amputations $[1,13,14]$. Socioeconomic factors are well known drivers of these diabetesrelated comorbidities. The poverty rate for AI/AN is among the highest in the USA [15]; their members experience greater poverty rates than the general US population ( $22 \%$ vs. $13 \%$, respectively) [16]. In Canada, First Nations people experience the highest levels of poverty; $25 \%$ live in poverty and $40 \%$ of Canada's Indigenous children live in poverty [17].

Both populations in the USA and Canada also experience other profound inequities that undermine their health and well-being [14, 18]. For example, AI/AN achieve lower rates of high school graduation and are less likely to obtain 4-year college or advanced degrees than the general US population ( $20 \%$ vs. $32 \%$, respectively) [16]. Similarly in Canada, only $72 \%$ of First Nations people living off reserve, $42 \%$ of Inuit, and $77 \%$ of Métis aged 18-44 had a high school diploma or equivalent compared to $89 \%$ of the non-Indigenous population [19]. Although the US government has a federal trust responsibility that includes the provision of healthcare to members of federally recognized tribes, access to quality healthcare is limited for many AI/ANs [20, 21]. In Canada, all citizens receive primary healthcare through its universal healthcare system through state and provincial governments [22]. Additional services known as Uninsured Health Benefits are provided by the federal government of Canada to registered or status Indians for First Nations individuals and Inuit recognized by an Inuit land claim organization as part of Canada's commitments under the United Nations Declaration of the Rights of Indigenous Peoples and the Truth and Reconciliation Commission's Calls to Action, Indigenous Services Canada [23]. Services (provided by the Indian Health Service [IHS] and Canada Health Act) are largely underfunded and under resourced [24-26]. In summary, AI/AN, First Nations, and Inuit members experience inequities due to social determinants of health and lack of healthcare access that undermine their health and well-being. Given the origins of these inequities, multi-component interventions for diabetes prevention and treatment are promising strategies to mitigate diabetes and related health inequities.

The US Healthy People 2030, which sets national objectives for the health and well-being of the population for the upcoming decade, has placed new emphasis on addressing social determinants of health through multi-level and multisector interventions [27, 28]. The social determinants of health are described as the conditions where people are born, live, learn, work, play, worship, and age [29, 30] and, for AI/ AN, also include implications of settler colonization, complicated eligibility rules for access to Native-specific healthcare services, and systemic racism [31-33]. Medical care for people with diabetes traditionally includes healthcare provider-offered individual-level diabetes self-management and care education, group-based education classes, prescription of oral or injectable medication (e.g., insulin), or a combination of these. However, a key shift in emphasis away from solely individual-level education has encouraged health educators to consider additional levels of influence (e.g., the food environment, policy, or involvement of community) that impact a person's ability to prevent and/or manage a chronic disease such as diabetes [34-37].

The Social Ecological Framework (or Model) is a multi-tier framework that organizes risk and protective factors which can then be used to inform multi-level prevention and treatment models for any given public health concern. Including micro to macro levels, the four strata are as follows: individual, relational (intrapersonal), community, and societal. This framework allows public health researchers and program implementers to consider the complex interplay and influential relationship one level has on another [38]. As supported by the Social Ecological Framework, an individual's health is influenced not only by individual factors, such as health-related knowledge and behavior, but also by additional factors at the interpersonal, organizational, community, and policy levels [38]. The US National Institutes of Minority Health and Health Disparities (NIMHD) health disparities research framework also supports multi-level factors affecting health. Manson and colleagues populated this framework illustrating the levels and dimensions that influence AI/AN health [39]. A compelling rationale has emerged for the need to address the social determinants of health to reduce health disparities through multi-level health interventions [40, 41]. However, implementing and evaluating multilevel health interventions are challenged by a number of circumstances, including the length of time required, multiple (sometimes conflicting) priorities of key parties involved, control of potentially confounding variables, program sustainability (e.g., cost), and varying levels of approvals and buy-in from key parties involved [41-43].

A scoping review methodology is best suited to answer the primary question before us: namely, "What is known in the existing literature about multi-level diabetes prevention and treatment interventions for Native peoples living in the United States and Canada?" [44]. Given the limited literature on this topic, especially with respect to outcomes, this scoping review included papers which describe multi-level interventions for diabetes prevention and/or treatment for Native peoples regardless of such data.

\section{Methods}

Methods used for this scoping review follow the Arksey and O'Malley Methodological Framework [44] and PRISMAScr guidelines [45]. Scoping literature reviews aim to 
identify the nature and extent of research evidence serve well as a preliminary assessment of the potential size and scope of available published literature. Scoping reviews can be used to identify gaps in existing literature, map the existing literature, and are especially useful when a body of literature is not developed enough for a traditional systematic review [44-46]. Four researchers and one medical librarian collaborated in all stages of this scoping review.

\section{Data Sources and Article Identification}

A comprehensive literature search was performed by a masters-trained medical librarian in May 2021. The medical librarian, co-author on this paper, met with other coauthors on two occasions to establish a search strategy, including identification of search terms. The medical librarian searched the following databases from the inception date of each database through May 11, 2021: MEDLINE (via Ovid MEDLINE® ALL, 1946 to search date), Embase (via Elsevier, 1947 to search date), Cochrane Central Register of Controlled Trials (via Wiley), CINAHL (Cumulative Index to Nursing and Allied Health Literature via EBSCOhost, 1981 to search date), and Web of Science Core Collection (via Clarivate Analytics, including Science Citation Index Expanded and Social Sciences Citation Index, 1974 to search date).

Databases were searched using a combination of keywords and database-specific indexing terms (when applicable) that represent the concepts of multi-level treatment and prevention interventions, diabetes mellitus, among AI/AN, First Nations, and Inuit people of Canada. Search terms were drafted by the librarian and refined through discussions with fellow co-authors. Searches were not limited by participant age, language, or publication date. Conference abstracts, editorial materials, magazines, and dissertations were excluded from this scoping review. See Table 1 for the Ovid Medline search strategy.

All search results were exported to EndNote 20 (Clarivate Analytics, Philadelphia, PA). Covidence systematic review software (Veritas Health Innovation, Melbourne, Australia) was used to de-duplicate database search results, for title and abstract screening, and identifying publications for full text review. The researchers then used Microsoft Excel 2020 (version 16.4) spreadsheet and Mendeley Reference Manager 2008 (version 1.19.4) to manage the references identified in this manner.
Table 1 Ovid Medline search strategy

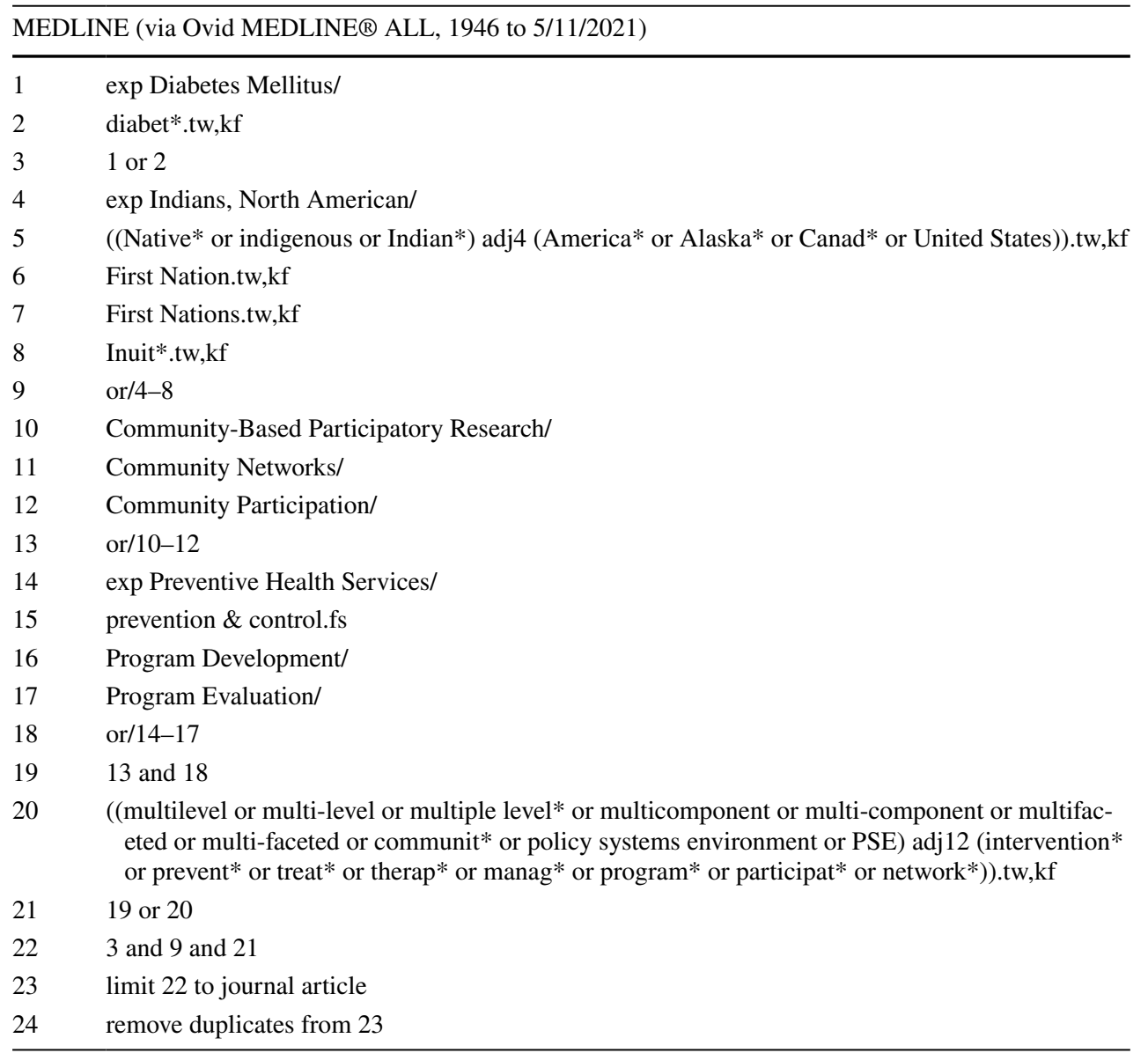




\section{Screening and Eligibility}

As suggested by Arksey and O'Malley [44], our search was first conducted with a broad range of synonyms as agreed upon by the research team. Key search terms, including synonyms, were diabetes mellitus, American Indian, Alaska Native, First Nations, multi-level, prevention, and treatment. Papers were screened in several phases. First, we conducted a manual search of all records to remove duplications that persisted after applying the automated de-duplication function. Two of us subsequently reviewed all titles and abstracts and removed records for which full text was not available (e.g., those that were publicly available grant proposals and conference proceedings) and those that did not meet the inclusion criteria. We next met with the entire team to discuss candidate abstracts and to determine eligibility for inclusion in the scoping review. To be eligible for full review, records had to be published in the English language before May 11, 2021, involve human subjects research, be published any time, and include Native peoples in the USA or Canada. Additionally, eligible papers had to be focused on multi-level diabetes treatment or prevention. We excluded studies that focused on a single level (e.g., individual) of intervention and those which did not specify diabetes as a key focus for prevention or treatment. For example, several multi-level obesity prevention papers were identified, but were not included because they lacked specific emphasis on diabetes prevention or treatment. Because so few papers met eligibility criteria, we included papers that did not report intervention outcomes, including papers that detailed the development or implementation of a multi-level diabetes prevention program, even if there were no outcomes reported. Additionally, because several interventions were discussed in more than one paper, we grouped all papers discussing the same intervention together by intervention title.

\section{Data Abstraction}

Data were abstracted by four independent researchers using the customized Microsoft Excel file capturing information about the following domains: title, publication year, first author, priority population, type of paper, study design, age of participants, multi-level components, diabetes (prevention/treatment), include in scoping review (yes/no), and include in background (yes/no). All four researchers discussed results during two group Zoom sessions; two of us met twice more to review discrepancies as they arose.

\section{Results}

A total of 1,095 articles were identified from the four databases and uploaded to Covidence. The software was used to detect and discard duplicates $(N=616)$, resulting in 479 articles that were screened by two co-authors for relevancy by reviewing abstract and title. The final number of articles selected for full-text review was 36 . Three co-authors read each of the 36 articles to extract key information such as if they were specific to diabetes, AV/AN, First Nations, or Inuit people and included multi-level intervention components. From this screening, 10 multi-level diabetes prevention or treatment interventions were identified as eligible to include in the scoping review, though several interventions had more than one associated article. At this point, the librarian conducted a cited reference search of these publications through Web of Science on June 9, 2021, to identify potentially relevant publications that were not included in the original database searches. This resulted in the inclusion of two additional articles, each associated with one of the 10 interventions identified through the original search. In total, 16 articles from 10 interventions are included in this scoping review. See Fig. 1 for the PRISMA flow diagram that provides details on the identification of publications and final numbers of studies and reports included in the scoping review.

Articles included in this scoping review were published between 1997 and 2021. In total, 16 records were included, encompassing 10 unique multi-level diabetes prevention or treatment interventions for AI/AN, First Nations, or Inuit people. Seven interventions had only one associated article [47-53]; another intervention had three articles [54-56], a third intervention had four associated articles [57-60], and a fourth intervention had two articles [61, 62]. Four of the interventions included were only represented by articles which describe the intervention $[48,49]$ or only an overview of program design and feasibility [51, 52]. Outcomes were presented in articles for the remaining 6 interventions, and study designs included a wide range such as a quasi-experimental design [47, 50], pre-/ post-study design [54-56], longitudinal cross sectional [59, 61, 62], and one randomized pilot study with a control group [53]. Four of the interventions took place in Canada [47, 50, 57-60] and six in the USA [48, 49, 51, 53-56, 61, 62].

Eight of the ten interventions focused on diabetes prevention for school-aged youth. Of these, seven included a school-based approach which focused on classroom education, increasing physical activity and healthy eating at school, and stress reduction [48-50, 52, 53, 57-62]. One diabetes prevention intervention for 10-19-year-old youth in two Native communities did not focus on a school-based education approach; instead, they included individual and family home-based education in conjunction with community-level activities [54-56]. Of the seven school-based approaches for diabetes prevention among youth, all included additional levels of intervention from family-based, community (e.g., church, social events, health fairs) levels to environmental levels (e.g., walking trails, improved selection of healthful foods in vending machines or stores). Several of these youth-focused diabetes prevention interventions also included policy changes such as increasing physical activity in schools [48], changing school meals to be healthier [49, 57, 59], and allowing only healthier foods and beverages in school vending machines [53, 61]. Two of the ten interventions prioritized 


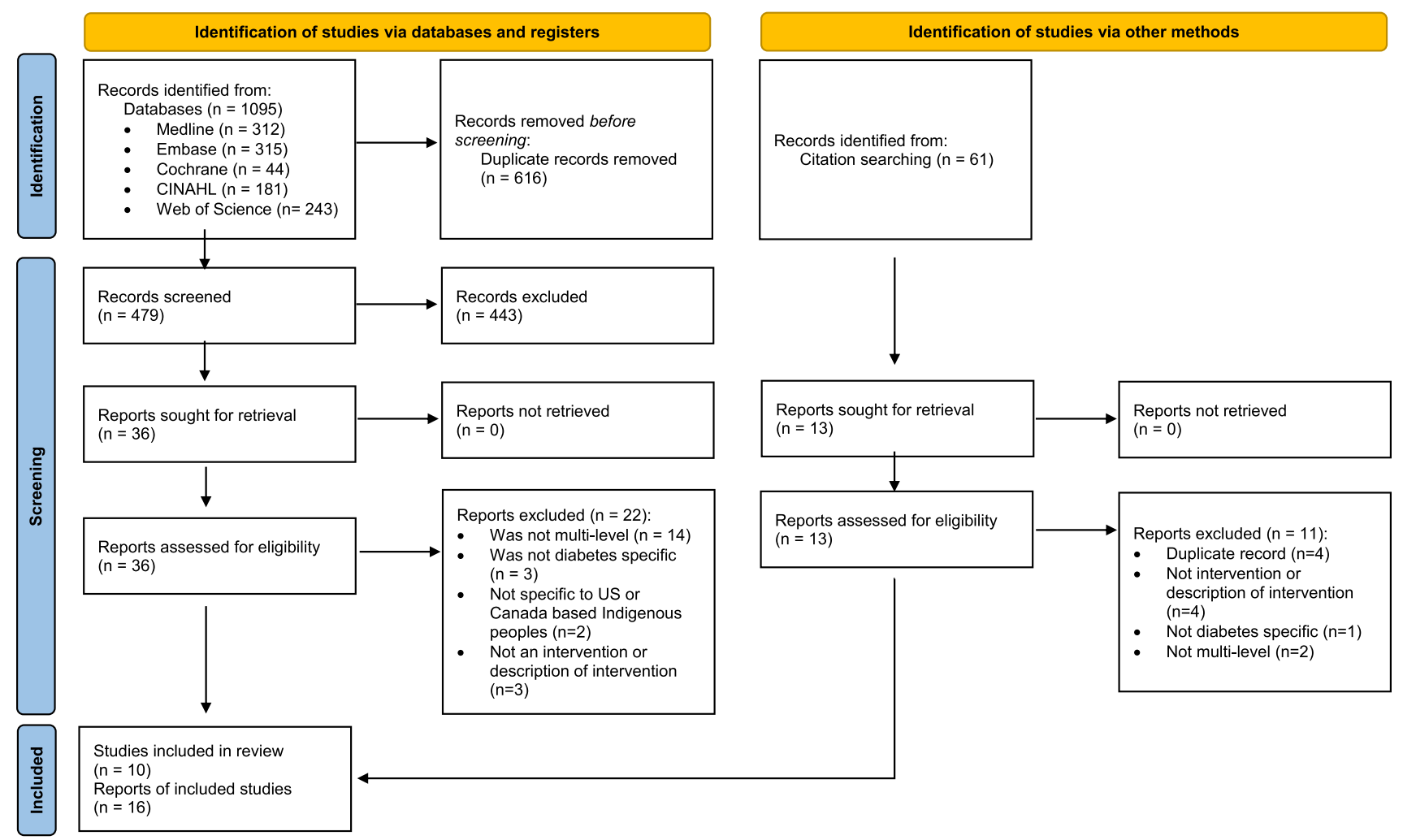

Fig. 1 PRISMA 2020 flow diagram for new systematic reviews which included searches of databases, registers, and other sources

adults as their key intended audience [47, 51]. These included individual clinic-based education; community exercise classes; worksite wellness programs; the provision of healthy foods at community Pow-wows or other community celebrations; and newspaper, radio, and social media campaigns for healthy eating and increased physical activity [47, 51]. Of note, none of the ten interventions focused exclusively on diabetes management for participants living with diabetes.

All of the included articles discussed the importance of community-based participatory research (CBPR) approaches to diabetes prevention/treatment interventions. Most emphasized the importance of including culturally relevant, culturally tailored, or culturally appropriate methods and delivery mechanisms. We noted no general trend or collective improvement in any outcomes measured across all of the articles included in this scoping review. Key intervention outcomes were not presented in some articles that instead focused on program description or implementation. Of the articles that presented outcomes, some included anthropometric measures such as weight and height (body mass index [BMI]) [47, 50, $53,55,56,59]$, triceps skinfold [59], and waist circumference [53]. Other articles included clinical measurements of blood pressure [47] and biochemical/cardiometabolic indicators such as levels of Hemoglobin A1c (HbA1c), fasting glucose, and fasting insulin [53, 56, 62]. Collectively, these articles presented mixed findings on the efficacy of any given intervention for improving BMI or associated diabetes-related laboratory values (e.g., HbA1c). These articles described a compelling need for additional research, more rigorous evaluation, and longer-term follow-up to determine the efficacy of diabetes prevention interventions for improving anthropometric markers of obesity and clinical and laboratory measures of intermediate diabetes outcomes. Several of the articles included outcomes such as changes in: nutrition related knowledge [47, 48, 52, 54], intention or receptiveness to making dietary changes [49,52], self-reported outcomes such as dietary changes [47, 56, 57], reduction in sedentary behavior or screen time [52, 57], minutes of self-reported physical activity performed pre/post intervention [47, 54, 59], and vending machine sales data [62].

Lessons learned, limitations, and recommendations for the next steps in multi-level diabetes prevention/treatment interventions were extracted from each article. Common themes emerged: Namely, interventions need to be designed by community members for optimal uptake and engagement [48, 52]; enough time needs to be provided to adequately plan, develop, implement, and evaluate these interventions $[47,48,50]$; sustainability is a concern (e.g., cost of healthy food, funding mechanisms) [52, 53]; and profound limitations to program evaluation (e.g., lack of control group, recruitment/retention) [53, 54, 59, 61]. Relevant details can be found in Table 2 . 


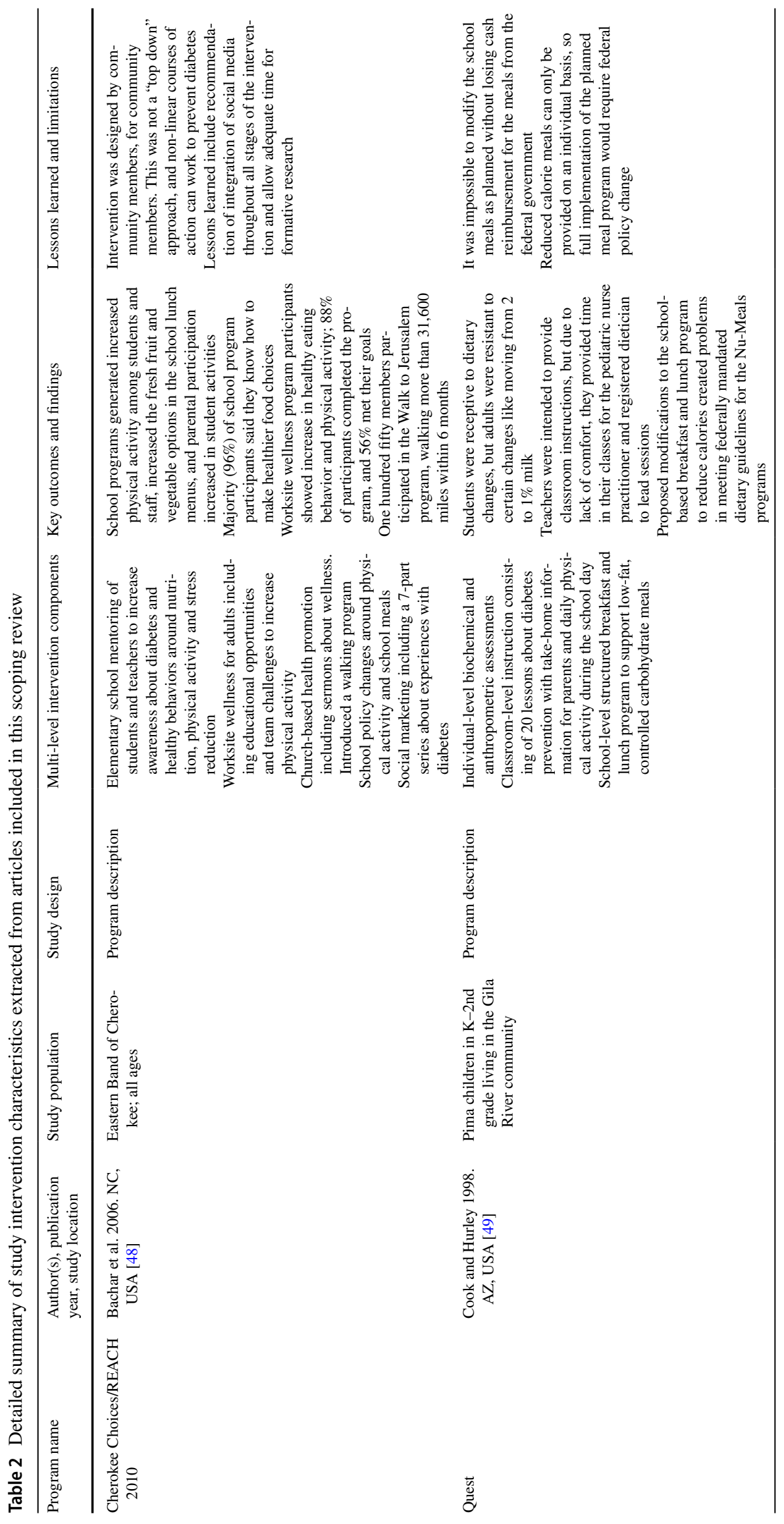




\section{Discussion}

As evidenced by this scoping review, little literature considers multi-level diabetes prevention and treatment interventions designed to serve the AI/AN, First Nations, and Inuit peoples of the USA and Canada. However, as early as the late 1990s, researchers have understood the importance of addressing multi-level factors that influence health, as demonstrated by the early work of several scholars included in this scoping review [47, 49, 57, 61]. Additionally, scholars and experts have long called for health promotion interventions that focus on the social determinants that exacerbate health disparities among this special population [41, 63]. Social determinants specific to diabetes prevention and treatment include access to healthful food and safe places to engage in physical activity. Seminal work on this topic includes Jernigan's work in Oklahoma which addresses food deserts and food insecurity as they impact nutrition-related chronic disease health disparities (e.g., hypertension, diabetes) through an innovative grocery store intervention $[64,65]$ and Gittelsohn's work on obesity prevention through a multi-institutional obesity control and prevention intervention for American Indian adults [66-68]. Likewise, Curran et al. conducted an innovative environmental level obesity reduction intervention on two American Indian reservations to improve healthy food access at local food suppliers (e.g., grocery and corner stores) [69]. However, because these interventions were not specific to diabetes prevention or management, they were not included in this present scoping review.

When determining appropriate search terms to conduct this review, we noted the challenge of differentiating between community-based participatory research (CBPR) or community-based approaches with multi-level interventions. The emphasis of CBPR is to join the community with researchers as full and equal partners in all phases of the research process and is especially effective when working with underserved, marginalized, or vulnerable populations $[70,71]$. Though it is widely accepted that health interventions are best received, utilized, and most effective when designed with CBPR or community-centered approaches, CBPR is not synonymous with multilevel approaches. The importance of CBPR approaches is especially well supported for work with Native peoples [72-75]. Several well-designed, community-based, diabetes treatment [76] and prevention programs [77] suggested positive outcomes but were excluded from this scoping review as they only addressed one level of intervention (e.g., the community level). Additionally important to note, group-based diabetes prevention classes, such as those featured in diabetes prevention program-like interventions, are typically focused only on the individual level albeit in a group-based setting [78, 79], unless they are intentionally paired with another level of intervention.

School-based approaches to diabetes prevention were the most common level of intervention evident in the literature. Gillies et al. [80] conducted a scoping review in 2020 specific to school-based nutrition interventions for Indigenous children in Canada, and though the focus of this scoping review was not specific to diabetes, their relevant findings indicated schools are an excellent venue to implement individual (e.g., education), community (e.g., family-based activities), environment/policy (e.g., vending machines within schools and school meal nutrient requirements) level interventions as a multi-level approach to nutrition-related chronic disease prevention [80]. In our scoping review, $70 \%$ of the interventions were schoolbased and included at least one of the aforementioned accompanying levels of intervention delineated by Gillies et al.

As noted by the authors of articles included in this scoping review, many challenges exist in implementing and evaluating multi-level health interventions for Native peoples. These challenges are well-supported in the literature and align with challenges related to CBPR approaches to health promotion $[41,72,81]$. Of these challenges, the time and financial resources needed to engage in robust CBPR, program design, implementation, and evaluation are most frequently cited [41, 47, 48, 50]. Challenges to program evaluation include participant recruitment, retention, and control of confounding variables $[41,53,59,61]$. Finally, multi-level approaches often require multi-organization/ institutional collaboration. Securing buy-in from varying key parties and competing priorities among these organizations introduce special challenges to the design, evaluation, and long-term sustainability of these interventions (e.g., school vs. local grocery store priorities) [40, 43, 82].

\section{Conclusions}

The worldwide COVID-19 pandemic placed a spotlight on disparities in health inequities and social determinants that impact these health disparities, leading to a renewed emphasis on addressing social determinants of health to reduce health disparities [83-85]. As supported by the Social Ecological Framework [38], NIMHD research frameworks [39], the Centers for Disease Control and Prevention [86], and US Healthy People 2030 [27, 30], researchers and interventionists should consider multi-level approaches with well-designed, appropriately funded evaluation strategies for diabetes prevention and treatment interventions. In addition, we should work in equitable and collaborative partnership with the communities we hope to serve. 


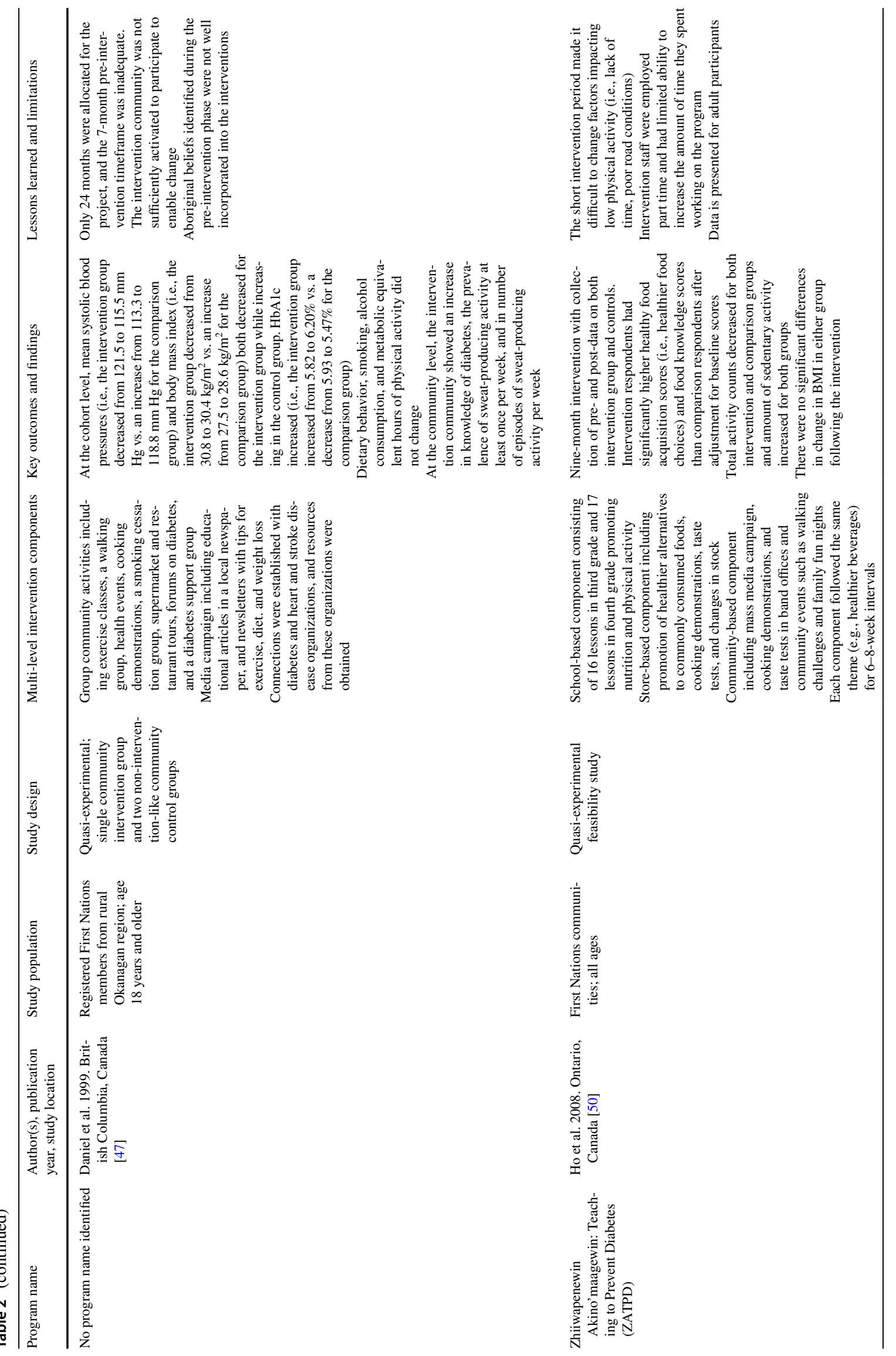




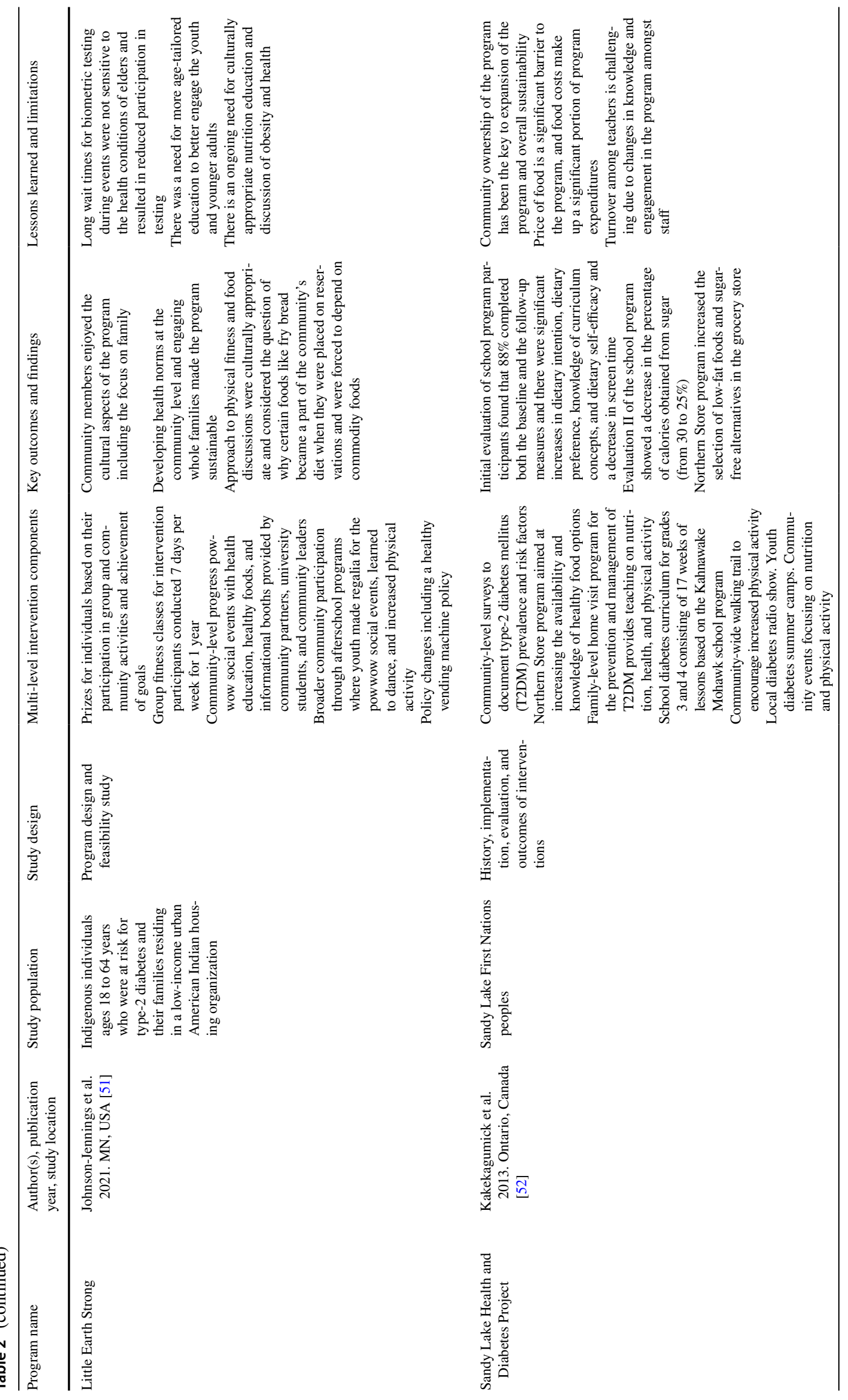




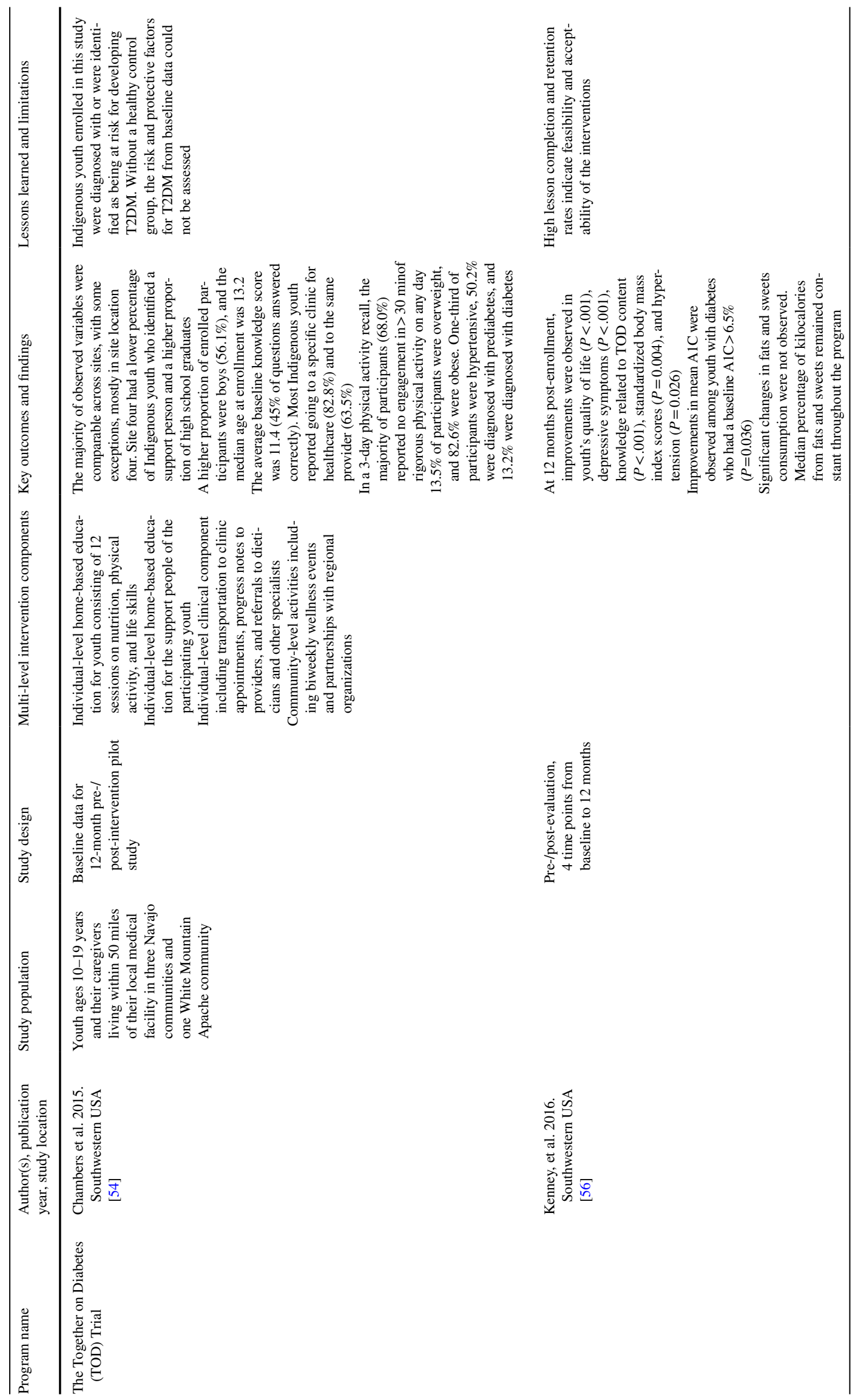




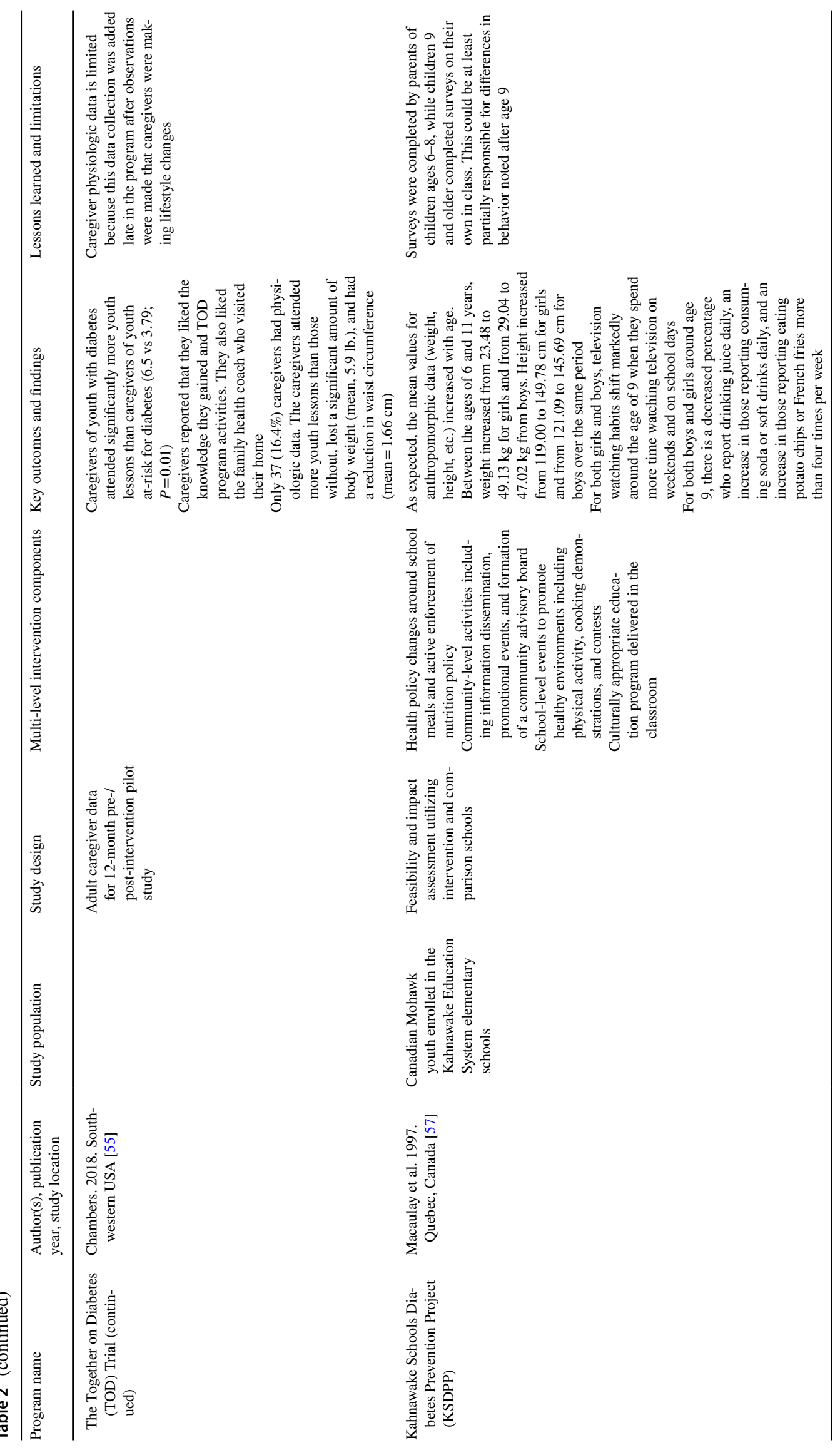



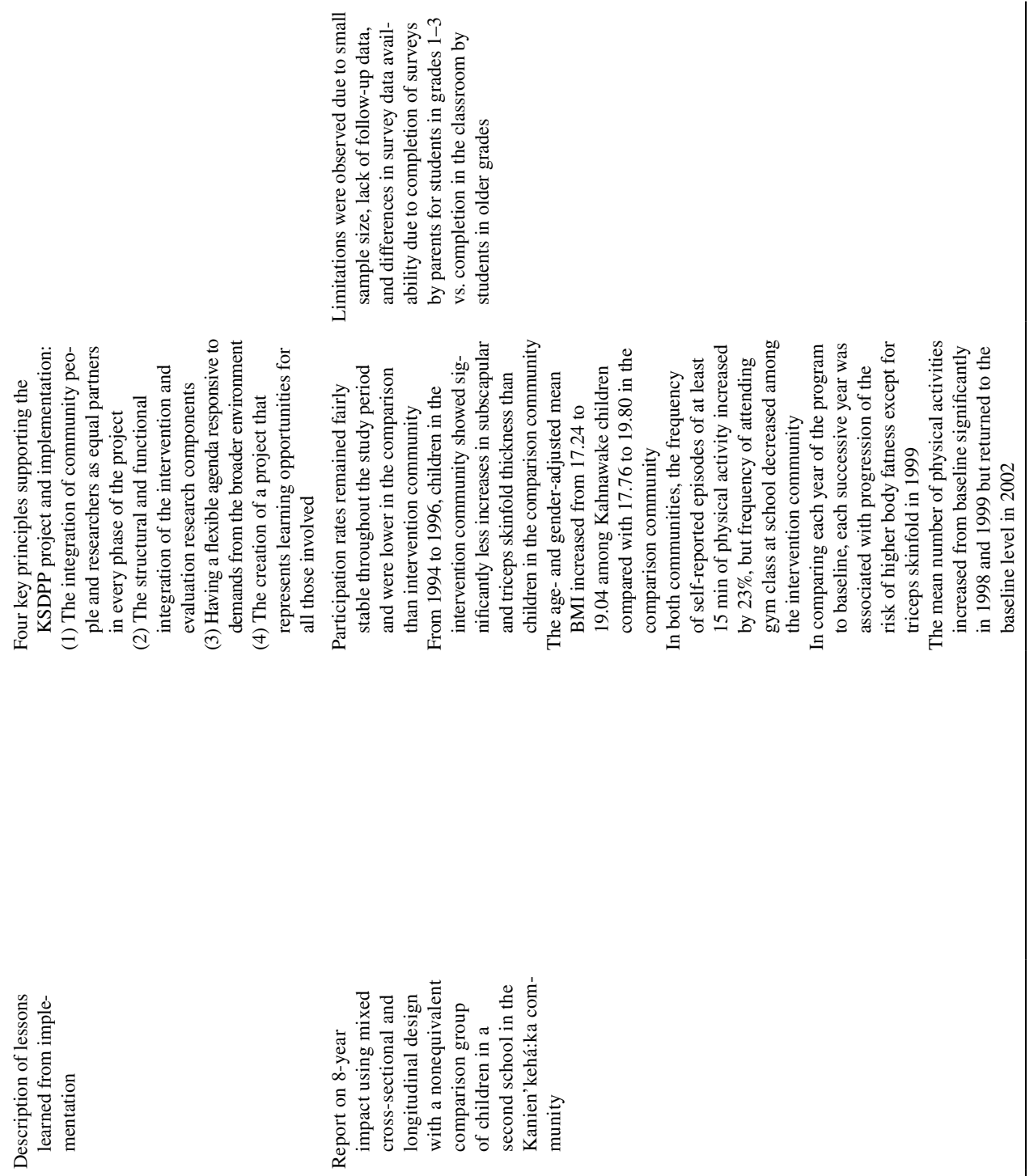

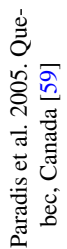

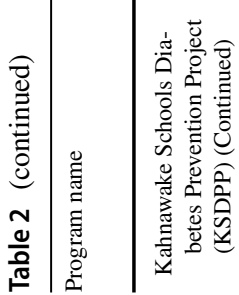



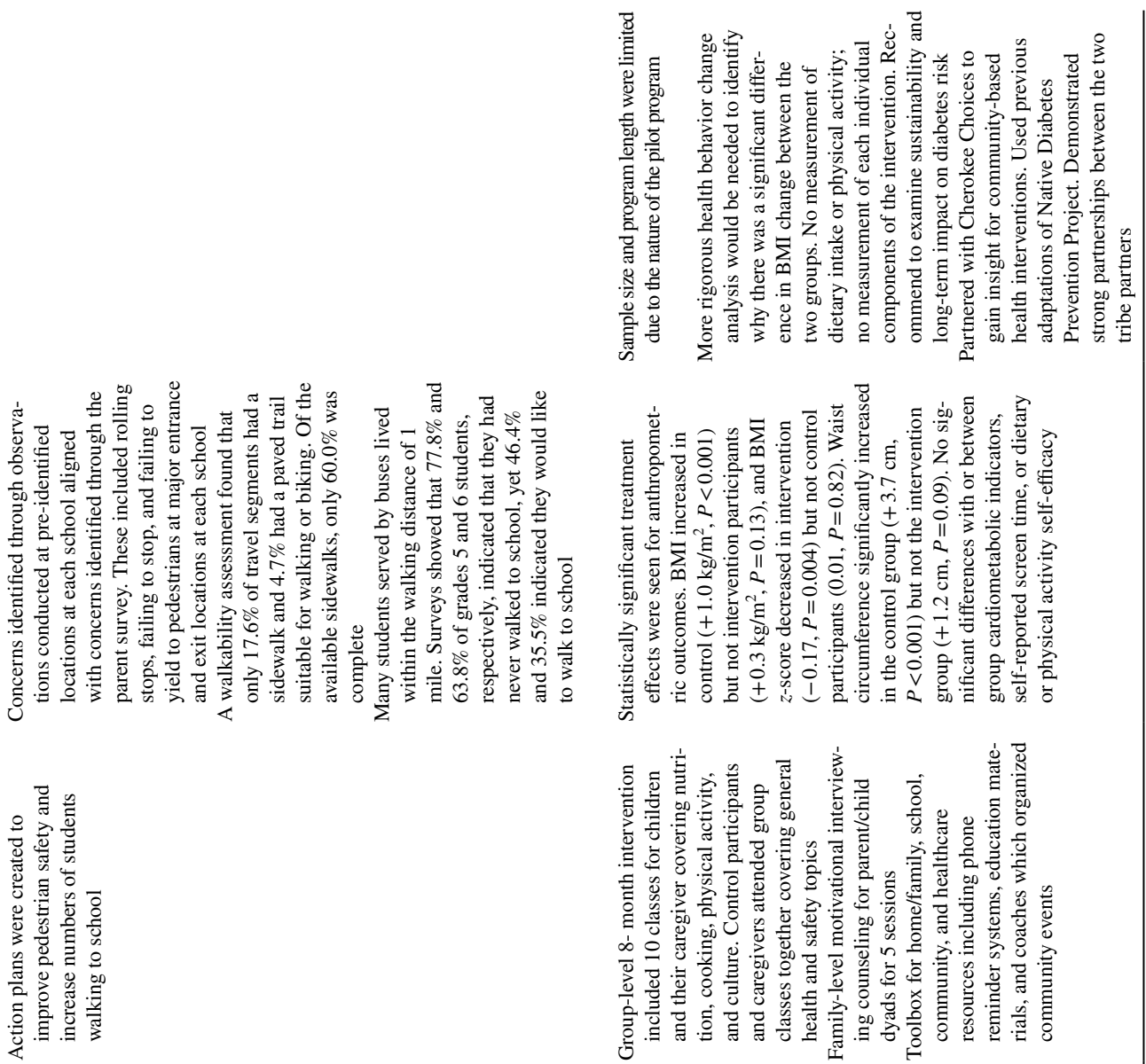

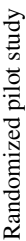
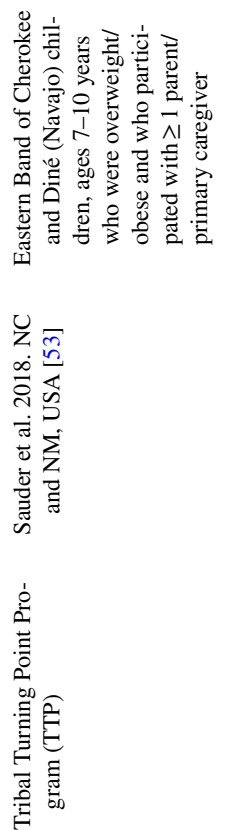


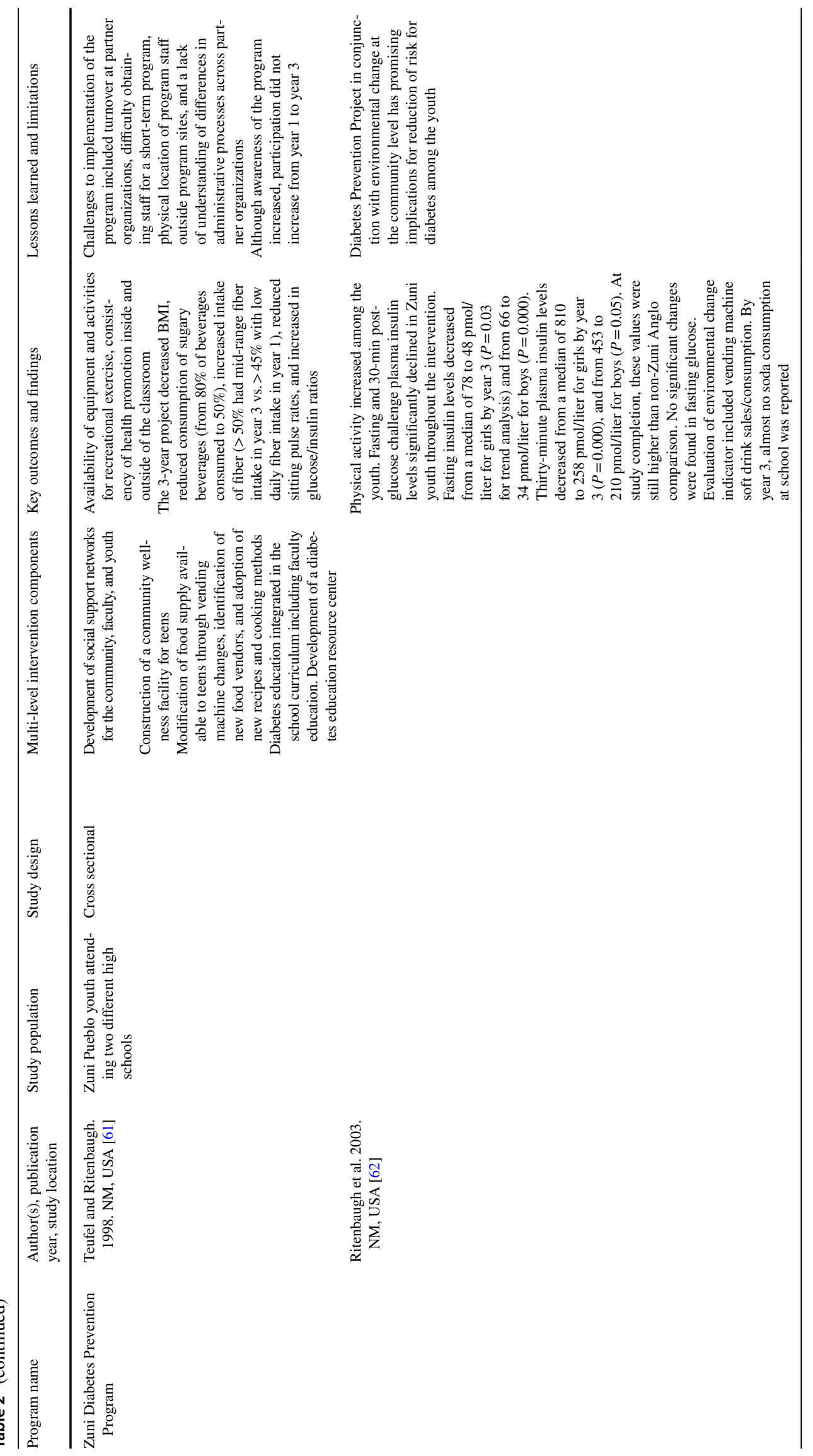




\section{References}

1. Halseth R. The prevalence of type 2 diabetes among First Nations and considerations for prevention. National Collaborating Centre for Aboriginal Health. Child Youth \& Family Health. 2019. https://www.nccih.ca/docs/health/RPT-Diabetes-First-NationsHalseth-EN.pdf. Accessed 4 October 2021.

2. Centers for Disease Control and Prevention. National diabetes statistics report, 2020 [Internet]. National Diabetes Statistics Report.Atlanta, GA; 2020. Available from: https://www.cdc.gov/ diabetes/pdfs/data/statistics/national-diabetes-statistics-report.pdf. Accessed 4 October 2021.

3. Burrows NR, Geiss LS, Engelgau MM, Acton KJ. Prevalence of diabetes among Native Americans and Alaska Natives, 1990 1997: an increasing burden. Diabetes Care. 2000;23(12):1786-90.

4. Centers for Disease Control and Prevention. National diabetes statistics report 2020 - estimates of diabetes and its burden in the United States [Internet]. Atlanta, GA; 2020. Available from: https://www.cdc.gov/diabetes/pdfs/data/statistics/national-diabe tes-statistics-report.pdf. Accessed 4 October 2021.

5. Walker JD, Slater M, Jones CR, Shah BR, Frymire E, Khan $S$, et al. Diabetes prevalence, incidence and mortality in First Nations and other people in Ontario, 1995-2014: A populationbased study using linked administrative data. Can Med Assoc J. 2020;192(6):E128-35.

6. Jiang L, Huang H, Johnson A, Dill EJ, Beals J, Manson SM, et al. Socioeconomic disparities in weight and behavioral outcomes among American Indian and Alaska Native participants of a translational lifestyle intervention project. Diabetes Care. 2015;38(November):2090-9.

7. Rith-Najarian S, Dannels E, Acton K. Preventing amputations from diabetes mellitus: the Indian Health Service experience. West Indian Med J. 2001;50(Supplement 1):41-3.

8. Narva A, Kuracina T. Chronic kidney disease is a public health issue. Indian Health Service Provider. 2002;27(9). https://www. ihs.gov/sites/provider/themes/responsive2017/display_objects/ documents/2000_2009/PROV0902.pdf. Accessed 4 October 2021.

9. Rhoades DA, Welty TK, Wang W, Yeh F, Devereux RB, Fabsitz RR, et al. Aging and the prevalence of cardiovascular disease risk factors in older American Indians: The Strong Heart Study. J Am Geriatr Soc. 2007;55(1):87-94.

10. Zhang Y, Galloway JM, Welty TK, Wiebers DO, Whisnant JP, Devereux RB, et al. Incidence and risk factors for stroke in American Indians the Strong Heart Study. Circulation. 2008;118(15):1577-84.

11. Howard B, Lee E, Cowan L, Devereux R, Galloway J, Go O, et al. Rising tide of cardiovascular disease in American Indians. Circulation. 2012;99(18):2389-95.

12. Bursell SE, Fonda SJ, Lewis DG, Horton MB. Prevalence of diabetic retinopathy and diabetic macular edema in a primary carebased teleophthalmology program for American Indians and Alaskan Natives. PLoS ONE. 2018;13(6):1-18.

13. Wilson C, Brown T, Acton K, Gilliland S. Effects of clinical nutrition education and educator discipline on glycemic control outcomes in the Indian Health Service. Diabetes Care. 2003;26(6):2500-4.

14. Crowshoe L, Dannenbaum D, Green M, Henderson R, Naqshbandi Hayward M, Toth E. Diabetes Canada 2018 Clinical practice guidelines for the prevention and management of diabetes in Canada: type 2 diabetes and Indigenous peoples. Can J Diabetes. 2018;42(Suppl 1):S296-306.

15. Income, Poverty and Health Insurance Coverage in the United States: 2015 [Internet]. United States Census Bureau. 2016 [cited 2017 Jan 12]. Available from: https://www.census.gov/newsroom/
press-releases/2017/income-povery.htmlAccess date 4 October 2021

16. US Census Bureau. Selected population profile in the United States: 2017 American community survey 1-year estimates. [Internet]. Census Bureau American FactFinder Advanced Search. [cited 2019 Apr 1]. Available from: https://factfinder.census.gov/ faces/tableservices/jsf/pages/productview.xhtml?pid=ACS_17_ 1YR_S0201\&prodType $=$ table.

17. Canadian Poverty Institute. Poverty in Canada [Internet]. [cited 2021 Jun 27]. Available from: https://www.povertyinstitute.ca/ poverty-canada.

18. Jiang L, Huang H, Johnson A, Dill EJ, Beals J, Manson SM, et al. Socioeconomic disparities in weight and behavioral outcomes among American Indian and Alaska Native participants of a translational lifestyle intervention project. Diabetes Care. 2015;38(11):2090-9.

19. Bougie E, Kelly-Scott K, Arriagada P. The education and employment experiences of First Nations people living off reserve, Inuit, and Métis: Selected findings from the 2012 Aboriginal Peoples Survey [Internet]. 2013. 77 p. Available from: http://www.statc an.gc.ca/daily-quotidien/131125/dq131125b-eng.pdf. Accessed 4 October 2021

20. Adamsen C. Native fact sheet health care coverage by age for American Indian / Alaska native elders. 2015. https://ruralhealth. und.edu/pdf/native-health-care-coverage.pdf. Accessed 4 October 2021.

21. Lillie-Blanton M, Roubideaux Y. Understanding and addressing the health care needs of American Indians and Alaska Natives. Am J Public Health. 2005;95(5):759-61.

22. Beckett M, Firestone MA, McKnight CD, Smylie J, Rotondi MA. A cross-sectional analysis of the relationship between diabetes and health access barriers in an urban First Nations population in Canada. BMJ Open. 2018;8(1):1-9.

23. Government of Canada. Benefits and rights for Indigenous peoples [Internet]. 2021 [cited 2021 Jun 27]. Available from: https://www. canada.ca/en/services/indigenous-peoples/benefits-and-rights-forindigenous-peoples.html. Accessed 4 October 2021.

24. O'Connell JM, Wilson C, Manson SM, Acton KJ. The costs of treating American Indian adults with diabetes within the Indian Health Service. Am J Public Health. 2012;102(2):301-8.

25. Government of Canada. Canada health act. Revised statutes of Canada. [Internet]. 1985 [cited 2021 Jun 27]. p. c. C-6. Available from: https://laws-lois.justice.gc.ca/eng/acts/c-6/page-1.html. Accessed 4 October 2021.

26. Caron S. Addressing the disparities in health care and health outcomes between Indigenous and non-Indigenous peoples in Canada [Internet]. University of Ottawa; 2020. Available from: http://hdl. handle.net/10393/40942. Accessed 4 October 2021.

27. US Department of Health and Human Services. Healthy people 2030 [Internet]. Office of Disease Prevention and Health Promotion. [cited 2020 Oct 3]. Available from: https://health.gov/ourwork/healthy-people-2030. Accessed 4 October 2021.

28. American Public Health Association. Healthy people 2030 charts new course for nation. The Nation's Health [Internet]. 2020 Oct; Available from: https://thenationshealth.aphapublications.org/ content $/ 50 / 8$. Accessed 4 October 2021.

29. Ratcliff KS. The social determinants of health: looking upstream. 1st ed. Cambridge: Polity Press; 2017. p. 2-3.

30. Office of Disease Prevention and Health Promotion. Social determinants of health: know what affects health [Internet]. Healthy People 2020. 2019 [cited 2020 Jan 30]. Available from: https:// www.cdc.gov/socialdeterminants/index.htm. Accessed 4 October 2021.

31. Jernigan VBB, Peercy MT, Branam D, Saunkeah BR, Wharton $\mathrm{D}$, Winkleby MA, et al. Beyond health equity: achieving wellness 
within American Indian and Alaska Native communities. Am J Public Health. 2015;105:S374-6.

32. Satterfield D, Frank M. Health promotion and diabetes prevention in American Indian and Alaska Native communities -traditional foods project, 2008-2014. Morb Mortal Wkly Rep Suppl. 2016;65(1):4-10.

33. Hojjati A, Beavis ASW, Kassam A, Choudhury D, Fraser M, Masching R, et al. Educational content related to postcolonialism and indigenous health inequities recommended for all rehabilitation students in Canada: a qualitative study. Disabil Rehabil [Internet]. 2018;40(26):3206-16. https://doi.org/10.1080/09638 288.2017.1381185.

34. Holben DH, Marshall MB. Position of the academy of nutrition and dietetics: food insecurity in the United States. J Acad Nutr Diet. 2017;117(12):1991-2002.

35. Fain JA. 2017 National standards for diabetes self-management education and support (DSMES): revised and updated. Diabetes Educ. 2017;43(5):439.

36. Tagtow A, Herman D, Cunningham-Sabo L. Next-generation solutions to address adaptive challenges in dietetics practice: the I+PSE conceptual framework for action. J Acad Nutr Diet. 2021;1-10. https://doi.org/10.1016/j.jand.2021.01.018.

37. Honeycutt S, Leeman J, McCarthy WJ, Bastani R, Carter-Edwards $\mathrm{L}$, Clark $\mathrm{H}$, et al. Evaluating policy, systems, and environmental change interventions: lessons learned from CDC's prevention research centers. Prev Chronic Dis. 2015;12(10):1-11.

38. McLeroy K, Bibeau D, Steckler A, Glanz K. An ecological perspective on health promotion programs. Health Educ Q. 1988;15:351-77.

39. Manson SM. National institute for minority health and health disparities research framework adaptation - American Indian [Internet]. [cited 2020 May 25]. Available from: https://www.nimhd. nih.gov/about/overview/research-framework/adaptation-frame work.html. Accessed 4 October 2021.

40. Paskett E, Thompson B, Ammerman AS, Ortega AN, Marsteller J, Richardson DJ. Multilevel interventions to address health disparities show promise in improving population health. Health Aff. 2016;35(8):1429-34.

41. Jernigan VBB, D'Amico EJ, Duran B, Buchwald D. Multilevel and community-level interventions with Native Americans: challenges and opportunities. Prev Sci. 2020;21:65-73.

42. Cleary PD, Gross CP, Zaslavsky AM, Taplin SH. Multilevel interventions: study design and analysis issues. J Natl Cancer Inst Monogr. 2012;44:49-55.

43. Agurs-Collins T, Persky S, Paskett ED, Barkin SL, Meissner HI, Nansel TR, et al. Designing and assessing multilevel interventions to improve minority health and reduce health disparities. Am J Public Health. 2019;109(S1):S86-93.

44. Arksey H, O’Malley L. Scoping studies: Towards a methodological framework. Int J Soc Res Methodol Theory Pract. 2005;8(1):19-32.

45. Tricco AC, Lillie E, Zarin W, O'Brien KK, Colquhoun H, Levac $\mathrm{D}$, et al. PRISMA extension for scoping reviews (PRISMA-ScR): checklist and explanation. Ann Intern Med [Internet]. $2018 \mathrm{Sep}$ 4;169(7):467-73. Available from: https://doi.org/10.7326/ M18-0850.

46. Peters MDJ, Godfrey CM, Khalil H, McInerney P, Parker D, Soares CB. Guidance for conducting systematic scoping reviews. Int J Evid Based Healthc. 2015;13(3):141-6.

47. Daniel M, Green LW, Marion SA, Gamble D, Herbert CP, Hertzman C, et al. Effectiveness of community-directed diabetes prevention and control in a rural Aboriginal population in British Columbia. Canada Soc Sci Med. 1999;48(6):815-32.

48. Bachar J, Lefler L, Reed L, McCoy T, Bailey R, Bell R. Cherokee choices: a diabetes prevention program for American Indians. Prev Chronic Dis. 2006;3(3):A103.
49. Cook VV, Hurley JS. Prevention of type 2 diabetes in childhood. Clin Pediatr (Phila). 1998;37(2):123-30.

50. Ho LS, Gittelsohn J, Rimal R, Treuth MS, Sharma S, Rosecrans $\mathrm{A}$, et al. An integrated multi-institutional diabetes prevention program improves knowledge and healthy food acquisition in northwestern Ontario First Nations. Heal Educ Behav. 2008;35(4):561-73.

51. Johnson-Jennings M, Punjabi A, Paul K, Jones J, Jennings D. Little Earth Strong: a community-level, culturally appropriate diabetes prevention pilot targeting urban American Indians. Prog Community Heal Partnerships Res Educ Action. 2021;15(1):3-14.

52. Kakekagumick KE, Hayward MN, Harris SB, Saksvig B, Gittelsohn J, Manokeesic G, et al. Sandy lake health and diabetes project: a community-based intervention targeting type 2 diabetes and its risk factors in a First Nations community. Front Endocrinol (Lausanne). 2013;4(NOV):1-9.

53. Sauder KA, Dabelea D, Callahan RB, Lambert SK, Powell J, James R, et al. Targeting risk factors for type 2 diabetes in American Indian youth: the tribal turning point pilot study. Pediatr Obes. 2018;13(5):321-9.

54. Chambers RA, Rosenstock S, Neault N, Kenney A, Richards J, Begay $\mathrm{K}$, et al. A Home-visiting diabetes prevention and management program for American Indian youth: the Together on Diabetes trial. Diabetes Educ. 2015;41(6):729-47.

55. Chambers R, Rosenstock S, Walls M, Kenney A, Begay M, Jackson K, et al. Engaging Native American caregivers in youthfocused diabetes prevention and management. Prev Chronic Dis. 2018;15(6): $1-6$.

56. Kenney A, Chambers RA, Rosenstock S, Neault N, Richards J, Reid R, et al. The impact of a home-based diabetes prevention and management program on high-risk American Indian youth. Diabetes Educ. 2016;42(5):585-95.

57. Macaulay AC, Paradis G, Potvin L, Cross EJ, Saad-Haddad C, McComber A, et al. The Kahnawake Schools Diabetes Prevention Project: intervention, evaluation, and baseline results of a diabetes primary prevention program with a native community in Canada. Prev Med (Baltim). 1997;26(6):779-90.

58. Macridis S, Garcia Bengoechea E, McComber AM, Jacobs J, Macaulay AC. Active transportation to support diabetes prevention: expanding school health promotion programming in an Indigenous community. Eval Program Plann. 2016;56:99-108.

59. Paradis G, Lévesque L, Macaulay AC, Cargo M, McComber A, Kirby R, et al. Impact of a diabetes prevention program on body size, physical activity, and diet among Kanien'kehá:ka (Mohawk) children 6 to 11 years old: 8-year results from the Kahnawake Schools Diabetes Prevention Project. Pediatrics. 2005;115(2):333-9.

60. Potvin L, Cargo M, McComber AM, Delormier T, Macaulay AC. Implementing participatory intervention and research in communities: lessons from the Kahnawake Schools Diabetes Prevention Project in Canada. Soc Sci Med. 2003;56(6):1295-305.

61. Teufel NI, Ritenbaugh CK. Development of a primary prevention program: Insight gained in the Zuni diabetes prevention program. Clin Pediatr (Phila) [Internet]. 1998;37(2):131-41. https://doi.org/ 10.1177/000992289803700211.

62. Ritenbaugh C, Teufel-Shone NI, Aickin MG, Joe JR, Poirier S, Dillingham DC, et al. A lifestyle intervention improves plasma insulin levels among Native American high school youth. Prev Med (Baltim). 2003;36(3):309-19.

63. Kulhawy-Wibe S, King-Shier KM, Barnabe C, Manns BJ, Hemmelgarn BR, Campbell DJT. Exploring structural barriers to diabetes self-management in Alberta First Nations communities 11 Medical and Health Sciences 1117 Public Health and Health Services. Diabetol Metab Syndr. 2018;10(1):1-7.

64. Jernigan VBB, Salvatore AL, Styne DM, Winkleby M. Addressing food insecurity in a Native American reservation using 
community-based participatory research. Health Educ Res. 2012;27(4):645-55.

65. Jernigan VBB, Wetherill MS, Hearod J, Jacob T, Salvatore AL, Cannady $\mathrm{T}$, et al. Food insecurity and chronic diseases among American Indians in rural Oklahoma: the THRIVE study. Am J Public Health. 2017;107(3):441-6.

66. Gittelsohn J, Jock B, Redmond L, Fleischhacker S, Eckmann T, Bleich SN, et al. OPREVENT2: Design of a multi-institutional intervention for obesity control and prevention for American Indian adults. BMC Public Health. 2017;17(1):1-9.

67. Gittelsohn J, Jock B, Poirier L, Wensel C, Pardilla M, Fleischhacker $\mathrm{S}$, et al. Implementation of a multilevel, multicomponent intervention for obesity control in Native American communities (OPREVENT2): challenges and lessons learned. Health Educ Res. 2020;35(3):228-42.

68. Gittelsohn J, Kim EM, He S, Pardilla M. A food store-based environmental intervention is associated with reduced BMI and improved psychosocial factors and food-related behaviors on the Navajo Nation. J Nutr. 2013;143(9):1494-500.

69. Curran S, Gittelsohn J, Anliker J, Ethelbah B, Blake K, Sharma $\mathrm{S}$, et al. Process evaluation of a store-based environmental obesity intervention on two American Indian reservations. Health Educ Res. 2005;20(6):719-29.

70. Holkup PA, Tripp-Reimer T, Salois EM, Weinert C. Community-based participatory research: an approach to intervention research with a Native American community. Adv Nurs Sci. 2004;27(3):162-75.

71. Israel BA, Schulz AJ, Parker EA, Becker AB. Review of community-based research: assessing partnership approaches to improve public health. Annu Rev Public Health. 1998;19:173-202.

72. Tremblay MC, Martin DH, McComber AM, McGregor A, Macaulay AC. Understanding community-based participatory research through a social movement framework: a case study of the Kahnawake Schools Diabetes Prevention Project. BMC Public Health. 2018;18(1):1-17.

73. Jernigan VBB. Community-based participatory research with Native American communities: the chronic disease self-management program. Health Promot Pract. 2010;11(6):888-99.

74. Delafield R, NacapoyHermosura A, Ing CT, Hughes CK, Palakiko DM, Dillard A, et al. A community-based participatory research guided model for the dissemination of evidence-based interventions. Prog Community Heal Partnerships Res Educ Action. 2016;10(4):585-95.

75. Chung-Do JJ, Look MA, Mabellos T, Trask-Batti M, Burke K, Mala Mau MKL. Engaging Pacific Islanders in research: community recommendations. Prog Community Heal Partnerships Res Educ Action. 2016;10(1):63-71.

76. Shah VO, Carroll C, Mals R, Ghahate D, Bobelu J, Sandy P, et al. A home-based educational intervention improves patient activation measures and diabetes health indicators among Zuni Indians. PLoS ONE. 2015;10(5):1-14.

77. Gray-Donald K, Robinson E, Collier A, David K, Renaud L, Rodrigues $\mathrm{S}$. Intervening to reduce weight gain in pregnancy and gestational diabetes mellitus in Cree communities: an evaluation. Can Med Assoc J. 2000;163(10):1247-51.

78. Tabak RG, Sinclair KA, Baumann AA, Racette SB, SebertKuhlmann A, Johnson-Jennings MD, et al. A review of diabetes prevention program translations: use of cultural adaptation and implementation research. Transl Behav Med. 2015;5(4):401-14.

79. The Diabetes Prevention Program Research Group. The diabetes prevention program (DPP). Diabetes Care. 2002;25(12):2165-71.

80. Gillies C, Blanchet R, Gokiert R, Farmer A, Thorlakson J, Hamonic $\mathrm{L}$, et al. School-based nutrition interventions for Indigenous children in Canada: a scoping review. BMC Public Health. 2020;20(1):1-12.

81. Jumper-Reeves L, Allen Dustman P, Harthun M, Kulis S, Brown E. American Indians' cultures: how CBPR illuminated inter-tribal cultural elements fundamental to an adaptation effort. Prev Sci. 2014;12(4):564-74.

82. Sallis JF. Needs and challenges related to multilevel interventions: physical activity examples. Heal Educ Behav. 2018;45(5):661-7.

83. Paremoer L, Nandi S, Serag H, Baum F. Covid-19 pandemic and the social determinants of health. Br Med J. 2021;372:1-5.

84. McNeely CL, Schintler LA, Stabile B. Social determinants and COVID-19 disparities: differential pandemic effects and dynamics. World Med Heal Policy. 2020;12(3):206-17.

85. Abrams EM, Szefler SJ. COVID-19 and the impact of social determinants of health. LancetRespir Med. 2020;8(7):659-61. https:// doi.org/10.1016/S2213-2600(20)30234-4.

86. Center for Disease Control and Prevention (CDC). CDC health disparities and inequalities report - United States, 2013. MMWR Morb Mortal Wkly Rep. 2013;62(3):1-186.

Publisher's Note Springer Nature remains neutral with regard to jurisdictional claims in published maps and institutional affiliations. 